\title{
DEVELOPMENT OF LEXICAL SEMANTIC AMONG PRESCHOOL EGYPTIAN ARABIC-SPEAKING CHILDREN
}

\author{
Dina M. Abd El Moneim, Hassan H. Ghandour, Dina A. Elrefaie, and \\ Mona S. Khodeir
}

\begin{abstract}
:
Phoniatrics Unit, Otorhinolaryngology Department, Faculty of Medicine, Ain Shams University, Cairo, Egypt

Corresponding author Dina Mohamed Abd El Moneim, Mobile: (+2) 01225989089

E.mail:

dr.dinamoneim91@gmail.com

Received: $1 / 2 / 2021$

Accepted: 24/2/2021

Background: Lexical-semantic development for preschool children has several applications in research design, assessment, and intervention that were very difficult to obtain before. In English and most Indo-European languages, there is a long tradition of examining aspects of child language by computing different developmental indices from spontaneous language samples and through applying different language tests. However, for the Arabic language, these aspects are lacking in this valuable area of research. Bridging this gap, this work provided the first comprehensive study of the Arabic language lexical-semantic development among preschool Egyptian Arabic speaking children.
\end{abstract}

Online ISSN: 2735-3540
Aim of the work: to provide a descriptive profile of the lexicalsemantic development among the preschool Egyptian Arabic-speaking children.

Subjects and methods: This is a descriptive cross-sectional study conducted on 120 typically developed Egyptian Arabic-speaking children. Children were randomly selected by inclusion and exclusion criteria in the age range between 2-4 years. Children were assessed by the lexical-semantic subtest of the standardized Egyptian Arabic Semantic Test (EAST). Children's total score and scores of the receptive and expressive aspects of the lexical-semantic subtest of EAST were calculated and compared to determine the development of the lexical-semantic among the 4 age-groups.

Results: A statistically significant difference was found between lexical-semantic growth among the 4 age groups. Lexical semantic growth is positively correlated to the chronological age of the participated children.

Conclusion: The lexical-semantic develops as early as the age of 2 years. Noun classes and verbs started to be identified by children at the age of 2 years. As children grow; noun vocabulary increases both expressively and receptively. Adjectives started to be acquired at age of 2.6 to 3 years and were mostly identified by the age of 3 to 3.6 years.

Keywords: Semantics Development, Lexical semantics, Arabicspeaking Children

\section{INTRODUCTION:}

As known, semantics is the study of meaning (1) and it is concerned with the meanings of linguistic expressions such as words, phrases, grammatical forms, and sentences $^{(2)}$. Semantics is divided into 3 subfields: lexical, grammatical, and conceptual semantics ${ }^{(3)}$. Lexical semantics 
focuses on 'content' words rather than 'grammatical' words. It is the meaning of words that belong to one of the four lexical word classes: nouns, verbs, adjectives, and adverbs, and the relation between these classes (lexical relations). Grammatical semantics studies aspects of meaning which have direct relevance to syntax including the meaning of the function words and inflectional affixes, grammatical functions, and the meaning of different sentencetypes ${ }^{(4)}$ While, conceptual semantics studies the relation between natural language and formal logical systems ${ }^{(5)}$. The fundamental goal of conceptual semantics is to describe how humans express their understanding of the world utilizing linguistic utterances ${ }^{(6)}$.

Studying lexical semantics needs to understand that words in a sentence could be lexemes or function words ${ }^{(7)}$. Lexemes are words that carry meaning individually and they include nouns, verbs, adjectives, and adverbs. The function words are words that have little lexical meaning, include articles, prepositions, and pronouns. They play role in the organization of the words and express grammatical relationships among other words within a sentence.

The most important for children in their earlier years are the lexical semantics. Lexical semantics indicates the child's language vocabulary knowledge and to what extent the child is familiar with his/her language words. Therefore, it indicates the ability of the child to identify and label words of several semantic classes, sort different words under its semantic classes, identify and label semantic classes according to their prototype. After that, the child could understand the word relationships, so he/she will be able to provide a synonym or an antonym for words, and understand the different word/sentence relations, and their meaning ${ }^{(6)}$.

Semantics increases students' understanding and awareness of word meaning, sentence relationships, discourse, and context. It also enables students to create and improve their semantics maps which are webs of words that visually display the meaning-based connections between a word or phrase and a set of related words or concepts $^{(8)}$.

Studies of the English language indicate that early comprehension vocabularies are larger than production vocabularies. At 16 months of age, children have comprehension vocabularies between 92 and 321 words. However, production vocabularies are typically 0 at 10 months and under 50 words at 16 months ${ }^{(9)}$.

Moreover, the content of verbs is more in children's comprehension vocabularies than in their production vocabularies, this imbalance occurs because communication works adequately with a minimal verb vocabulary $^{(\boldsymbol{9})}$. In Arabic-speaking societies, lexical semantics was not comprehensively assessed or described in any previous studies, and this was the motive for this study.

This work studies the development of the lexical-semantic among the preschool Egyptian Arabic children to have an indicative chart of the order, amount, and type of lexical semantics developed by those children. this will help phoniatricains and speech-language pathologists in determining the deficits of semantic development among children with delayed language development and help in designing a language therapy plan suitable for each child's age and deficits.

\section{AIM OF THE WORK:}

This study aims to provide a descriptive profile of the lexical-semantic development among the preschool Egyptian Arabicspeaking children. 


\section{PARTICIPANTS AND METHODS:}

This study was a cross-sectional descriptive study that was carried out at different nurseries in Cairo, Egypt in the period from December 2019 to February 2021.

\section{Participants:}

One hundred and twenty (120) Egyptian Arabic-speaking children (54 males and 66 females) representing different social classes and aged between 2 to 4 years old. They were randomly selected children from residents of Cairo, Egypt. They were divided into 4 age groups with a 6-month age interval between each group. Children's age range in group I was $2 \mathrm{y} .0 \mathrm{~m}$ to $2 \mathrm{y} .06 \mathrm{~m}$, group II was $2 \mathrm{y} .6 \mathrm{~m}$ to $3 \mathrm{y} .0 \mathrm{~m}$ group III was $3 y .0 \mathrm{~m}$ to $3 y 6 \mathrm{~m}$, and group IV were $3 \mathrm{y} 6 \mathrm{~m}$ to $4 \mathrm{y} 0 \mathrm{~m}$. Each group included 30 children.

All participating children in each group had average IQ and normal mental age as assessed by the screening test of StanfordBinet intelligence scale, Arabic version (5th edition) ${ }^{(\mathbf{1 0})}$. Children were checked to have normal or normal-corrected vision and normal peripheral hearing. Age-appropriate children with language and/or speech delay were subsequently excluded from the study. The inclusion and exclusion criteria were determined by the medical history taken from the children's parents, and clinical examination of the children.

All parents of children involved in this study have given their informed consent, and the study protocol has been approved by the Ain Shams Institute's Ethical Committee of Human Research.

\section{Methods:}

The lexical-semantic development was assessed by the lexical-semantic subtest of the standardized Egyptian Arabic Semantic Test "EAST" (17). EAST is a standardized comprehensive test that measures semantic development in preschool children $(2-4$ years old). The lexical-semantic subtest of this test was used to assess the development of different lexical semantic classes (nouns, adjectives, verbs) on both the receptive and expressive aspects, among the participated children in this study. Participated children were assessed for the ability to label and/or identify (by finger-pointing) the target pictures shown to them for the following semantic classes, family members, animals (including wild and farm animals, birds, insects, reptiles, sea creatures), plants, vegetables, fruits, common kinds of food, clothes, transports, electronic devices, furniture, common objects, body parts, colors, jobs, places, as well as routine action verbs and adjectives. Each semantic class was presented by 3- 4 pictures on each page using familiar colorful clear pictures.

The receptive and expressive aspects of the lexical-semantic subtest were assessed simultaneously. Firstly, the child was asked to label pictures of the expressive aspect shown to him/her by the examiner. If the child were not able to label these pictures, the examiner shifted to the receptive aspect and asked the child to identify the picture of the word the examiner told to him/her. Applying the test this way will shorten the test time, and keep the child concentrated as much as possible. The child will be given 1 point for each correct answer and 0 point for the incorrect answer. The scores will be divided into the score of the receptive parts and expressive parts, and the total score (summation of scores of both receptive and expressive parts). The total score of the lexical-semantic subtest is 306 (153 for the expressive aspect and 153 for the receptive aspect).

The test was applied to all children by a native Egyptian Arabic-speaking phoniatrician. During the assessment of younger children (below 3 years), the examiner needed to allow parents' participation with the instruction not to 
reword directions to the child or give the child cues to get the right answer.

\section{Statistical Analysis:}

Data were collected, revised, coded, and analyzed by the Statistical Package for Social Science (IBM SPSS) version 23. Means and standard deviation values were used to describe the quantitative data, and numbers and percentages were used to describe the qualitative data. The Analysis of One Variance "ANOVA" test and PostHoc test was used to compare the results of the four age groups, with p-value is significant at $<0.05 \mathrm{p}$-value is significant at $<0.05$ and highly significant at $<0.01$.
Pearson correlation coefficient was used to correlate the children's chronological ages to the scores of the receptive and expressive aspects of the lexical-semantic subtest of the EAST, with $p$-value is significant at $<0.05$ and highly significant at $<0.01$.

\section{RESULTS:}

The distribution of age and gender of the participated children among the 4 age groups is showed in Table 1. Children's scores of the receptive and expressive aspects of the lexical-semantic subtest of EAST including the mean and standard deviation are reported in Tables $\mathbf{2}$ and $\mathbf{3}$.

Table (1): The distribution of the age and gender of the participated children among the 4 age groups.

\begin{tabular}{|c|c|c|c|c|c|}
\hline \multicolumn{2}{|c|}{ Tested groups } & $\begin{array}{c}\text { Group 1 } \\
(\mathrm{n}=30)\end{array}$ & $\begin{array}{c}\text { Group 2 } \\
(\mathrm{n}=30)\end{array}$ & $\begin{array}{c}\text { Group 3 } \\
(\mathrm{n}=30)\end{array}$ & $\begin{array}{c}\text { Group 4 } \\
(\mathrm{n}=30)\end{array}$ \\
\hline \multicolumn{2}{|c|}{ Age range in years } & $(2-<2.6 y)$ & $(2.6-<3 y)$ & $(3-<3.6 y)$ & $(3.6-<4 y)$ \\
\hline \multicolumn{2}{|c|}{ Age, in years $($ mean $\pm S D)$} & $2.3( \pm 0.2)$ & $2.9( \pm 0.1)$ & $3.3( \pm 0.2)$ & $3.8( \pm 0.1)$ \\
\hline \multirow{2}{*}{$\begin{array}{l}\text { Gender } \\
\text { (No. \%) }\end{array}$} & Males & $13(43.3 \%)$ & $16(53.3 \%)$ & $11(36.7 \%)$ & $14(46.7 \%)$ \\
\hline & Females & $17(56.7 \%)$ & $14(46.7 \%)$ & $19(63.3 \%)$ & $16(53.3 \%)$ \\
\hline
\end{tabular}

Scores of the lexical-semantic subtest of EAST as shown in the form of (mean and SD) shown in tables $\mathbf{2}$ and 3, revealed that children at the age of 2 years started to identify noun and verb classes earlier than adjectives.

Adjectives started to be acquired at age of 2.6 to 3 years and became more richly identified by the age of 3 to 3.6 years.

Children at the age of 2 to 2.6 years could identify and label Family members (mainly mother and father and grandparents if they are alive), but they could not even identify sister and brother. However, they could identify all farms and most of the wild animals, but they could only label little (less than 3) of wild animals; the lion was the most familiar. They were also able to label most of the food kinds, and common objects (such as plate, spoon, money, and keys), and only the primary body parts only.

Although they were able to identify (by pointing) most of the vegetables and fruits, clothes, and transportations, they could not label most of them till the age of 2.6 to 3 years.

Insects, reptiles and plants, and common places were the difficult ones to label and identify by $2-2.6$-year aged children. As the children's age increase, more nouns and noun classes were added. Identifying jobs and colors are late to be acquired by the age of 3 - 3.6 years, but children could label them accurately by the age of 3.6 to 4 years old. The most difficult noun classes to be identified and labeled as insects and reptiles. Children at the age of $3.6-4$ years could only label some of them. 
Table (2): Mean and standard deviation (SD) values of the receptive aspect of the lexical-semantic subtest of EAST among the 4 age-groups, and comparison between their values using analysis of variance "ANOVA" test.

\begin{tabular}{|c|c|c|c|c|c|c|c|}
\hline \multirow{2}{*}{ Test parameters } & \multirow{2}{*}{$\begin{array}{l}\text { Total } \\
\text { scores }\end{array}$} & Group 1 & Group 2 & Group 3 & Group 4 & \multirow{2}{*}{$\begin{array}{c}\mathrm{t}- \\
\text { score }\end{array}$} & \multirow{2}{*}{$\mathrm{p}$-value } \\
\hline & & $($ mean $\pm \mathrm{SD})$ & $($ mean $\pm \mathrm{SD})$ & $($ mean $\pm \mathrm{SD})$ & (mean $\pm \mathrm{SD}$ & & \\
\hline 1)Nouns & 131 & $\begin{array}{c}108.17 \pm \\
16.34\end{array}$ & $\begin{array}{c}125.00 \pm \\
4.33\end{array}$ & $\begin{array}{c}126.50 \pm \\
4.26\end{array}$ & $\begin{array}{c}128.50 \pm \\
2.27\end{array}$ & 21.78 & $0.000^{* *}$ \\
\hline 2) Verbs & 12 & $10.60 \pm 1.83$ & $11.73 \pm 0.58$ & $11.83 \pm 0.46$ & $11.97 \pm 0.18$ & 37.88 & $0.000^{* *}$ \\
\hline 3)Adjectives & 10 & $6.83 \pm 3.27$ & $8.87 \pm 1.43$ & $9.70 \pm 0.70$ & $9.87 \pm 0.35$ & 36.35 & $0.000^{* *}$ \\
\hline $\begin{array}{l}\text { Total score of } \\
\text { lexical semantic } \\
\text { subtest }\end{array}$ & 153 & $\begin{array}{c}125.60 \pm \\
20.49\end{array}$ & $\begin{array}{c}145.60 \pm \\
5.10\end{array}$ & $\begin{array}{c}148.03 \pm \\
4.39\end{array}$ & $\begin{array}{c}150.33 \pm \\
2.48\end{array}$ & 41.83 & $0.000^{* *}$ \\
\hline
\end{tabular}

ANOVA test: * p-value is significant at $<0.05, * *$ p-value is highly significant at $<0.01$.

Table (3): Mean and standard deviation (SD) values of the expressive aspect of the lexical-semantic subtest of EAST among the 4 age-groups, and comparison between their values using analysis of variance "ANOVA" test.

\begin{tabular}{|l|c|c|c|c|c|c|c|}
\hline Test parameters & $\begin{array}{c}\text { Total } \\
\text { scores }\end{array}$ & $\begin{array}{c}\text { Group 1 } \\
(\text { mean } \pm \text { SD) }\end{array}$ & $\begin{array}{c}\text { Group 2 } \\
(\text { mean } \\
\pm \text { SD) }\end{array}$ & $\begin{array}{c}\text { Group 3 } \\
(\text { mean } \pm \text { SD) }\end{array}$ & $\begin{array}{c}\text { Group 4 } \\
(\text { mean } \pm \text { SD) }\end{array}$ & t-score & p-value \\
\hline 1)Nouns & 131 & $73.17 \pm 25.16$ & $\begin{array}{c}98.80 \pm \\
11.61\end{array}$ & $\begin{array}{c}107.70 \pm \\
13.23\end{array}$ & $\begin{array}{c}114.33 \pm \\
9.67\end{array}$ & 32.660 & $0.000^{* *}$ \\
\hline 2) Verbs & 12 & $7.03 \pm 3.53$ & $9.40 \pm 1.61$ & $10.77 \pm 1.36$ & $11.00 \pm 1.02$ & 54.671 & $0.000^{* *}$ \\
\hline 3)Adjectives & 10 & $2.90 \pm 3.17$ & $4.77 \pm 2.21$ & $7.00 \pm 1.93$ & $7.30 \pm 2.12$ & 42.655 & $0.000^{* *}$ \\
\hline $\begin{array}{l}\text { Total score of } \\
\text { lexical semantic } \\
\text { subtest }\end{array}$ & 153 & $83.10 \pm 30.41$ & $\begin{array}{c}112.97 \pm \\
12.97\end{array}$ & $\begin{array}{c}125.47 \pm \\
15.19\end{array}$ & $\begin{array}{c}132.63 \pm \\
11.51\end{array}$ & 55.444 & $0.000^{* *}$ \\
\hline
\end{tabular}

ANOVA test: $*$ p-value is significant at $<0.05, * * \mathrm{p}$-value is highly significant at $<0.01$.

By comparing the results of the total scores and scores of the receptive and expressive aspects, a statistically significant difference was found between the 4 studied age groups ( $\mathrm{p}$-value <0.01). The Post-Hoc test was done for further analysis of the difference between total scores of lexical semantic classes and scores of each subtest of the receptive and expressive parts of nouns, verbs, and adjectives among the four age groups. Table 4 revealed that there is a statistically significant difference between group I when compared to either group II, III, or IV as regard identification and labeling of all lexical semantic classes, the $\mathrm{p}$-value is highly significant at $<0.01$. There is a statistically significant difference when comparing group II to group III and IV as regards labeling all lexical semantic classes (nouns, verbs, and adjectives). no statistically significant difference was found when comparing group II to group III and IV as regards the identification of nouns and verbs (receptive part) as well as the total score of identification of lexical semantic classes (receptive part). However, there is a significant difference between group II and group IV as regards the identification of adjectives (receptive part). Also, comparing group III and group IV as regard identification and labeling of all lexical semantic classes. 
Table (4): Post-Hoc analysis and multi-comparison between the 4 age groups as regards the total score of identification and labeling of lexical semantic classes, identification and labeling of nouns, verbs, and adjectives.

\begin{tabular}{|l|c|c|c|c|c|c|}
\hline \multicolumn{7}{|c|}{ Post-Hoc analysis and multi-comparison between groups } \\
\hline Test parameters & $\begin{array}{c}\text { Group 1 versus } \\
\text { Group 2 }\end{array}$ & $\begin{array}{c}\text { Group 1 } \\
\text { versus } \\
\text { Group 3 }\end{array}$ & $\begin{array}{c}\text { Group 1 } \\
\text { versus } \\
\text { Group 4 }\end{array}$ & $\begin{array}{c}\text { Group 2 } \\
\text { versus } \\
\text { Group 3 }\end{array}$ & $\begin{array}{c}\text { Group 2 } \\
\text { versus } \\
\text { Group 4 }\end{array}$ & $\begin{array}{c}\text { Group 3 } \\
\text { versus } \\
\text { Group 4 }\end{array}$ \\
\hline Nouns (Receptive) & $0.000^{* *}$ & $0.000^{* *}$ & $0.000^{* *}$ & 0.510 & 0.126 & 0.380 \\
\hline Nouns (Expressive) & $0.000^{* *}$ & $0.000^{* *}$ & $0.000^{* *}$ & $0.034^{*}$ & $0.000^{* *}$ & 0.113 \\
\hline Verbs (Receptive) & $0.000^{* *}$ & $0.000^{* *}$ & $0.000^{* *}$ & 0.697 & 0.364 & 0.604 \\
\hline Verbs (Expressive) & $0.000^{* *}$ & $0.000^{* *}$ & $0.000^{* *}$ & $0.014^{*}$ & $0.004^{* *}$ & 0.670 \\
\hline $\begin{array}{l}\text { Adjectives } \\
\text { (Receptive) }\end{array}$ & $0.000^{* *}$ & $0.000^{* *}$ & $0.000^{* *}$ & 0.080 & $0.036^{*}$ & 0.725 \\
\hline $\begin{array}{l}\text { Adjectives score } \\
\text { (Expressive) }\end{array}$ & $0.003^{*}$ & $0.000^{* *}$ & $0.000^{* *}$ & $0.000^{* *}$ & $0.000^{* *}$ & 0.630 \\
\hline $\begin{array}{l}\text { Total } \\
\text { (Receptive) }\end{array}$ & $0.000^{* *}$ & $0.000^{* *}$ & $0.000^{* *}$ & 0.387 & 0.094 & 0.414 \\
\hline $\begin{array}{l}\text { Total score } \\
\text { (Expressive) }\end{array}$ & $0.000^{* *}$ & $0.000^{* *}$ & $0.000^{* *}$ & $0.013 *$ & $0.000^{* *}$ & 0.148 \\
\hline
\end{tabular}

Post-Hoc test: $*$ p-value is significant at $<0.05, * *$ p-value is highly significant at $<0.01$.

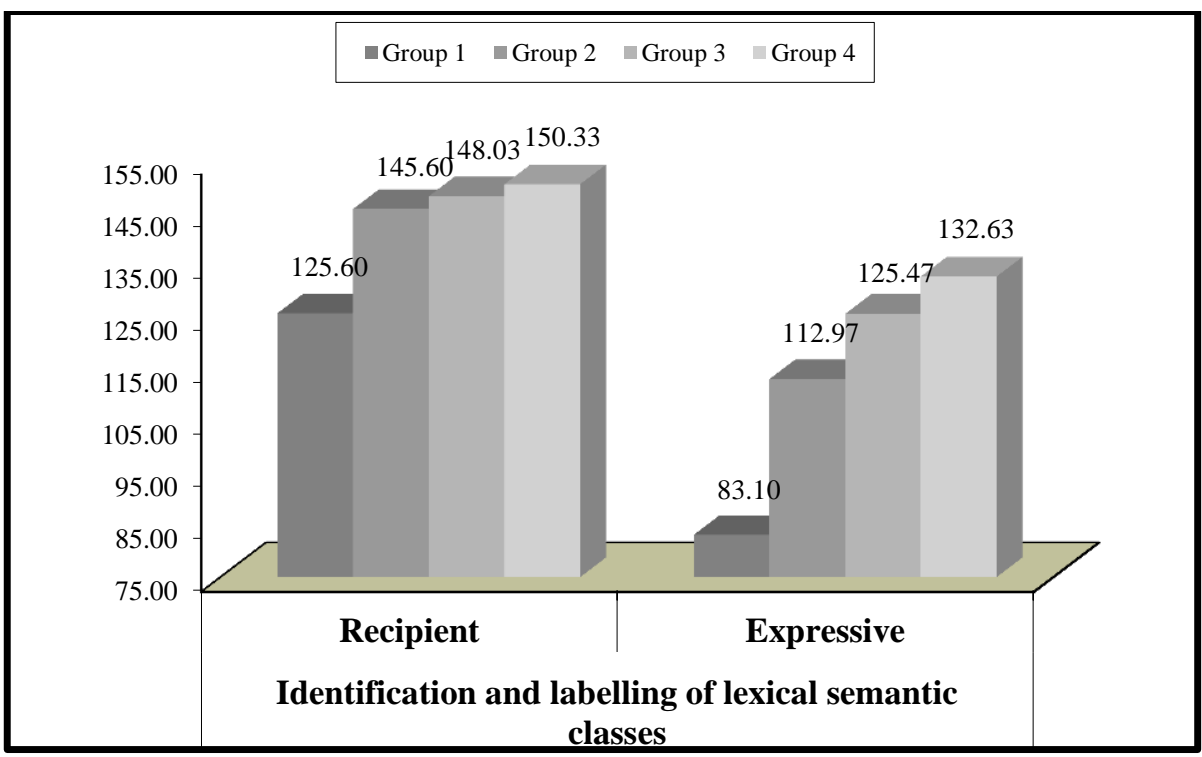

Figure (4): Comparison of the scores of the lexical-semantic subtest among the 4 age-groups.

Pearson correlation coefficient revealed a positive correlation was found between the scores identification and labeling of all lexical-semantic classes (nouns, verbs, and adjectives) and the chronological age of the participated children, Table (5). This indicates that as the children age increases their lexical-semantic knowledge increased too. 
Table (5): Correlation between total scores of the receptive and expressive parts to the chronological age of the participated children among the 4 age groups, using Pearson correlation coefficient.

\begin{tabular}{|l|c|c|c|c|}
\hline \multicolumn{4}{|c|}{ Pearson correlation coefficient } \\
\hline \multirow{3}{*}{ Test parameters } & \multicolumn{4}{|c|}{ Mean age of participated children } \\
\cline { 2 - 5 } & \multicolumn{2}{|c|}{ Receptive part } & \multicolumn{2}{c|}{ Expressive part } \\
\cline { 2 - 5 } & $\mathrm{r}-$ & $\mathrm{p}$-value & $\mathrm{r}$ - & $\mathrm{p}$-value \\
\hline Nouns & $0.571^{* *}$ & 0.000 & $0.665^{* *}$ & 0.000 \\
\hline Action verbs & $0.388^{* *}$ & 0.000 & $0.468^{* *}$ & 0.000 \\
\hline Adjectives & $0.477^{* *}$ & 0.000 & $0.530^{* *}$ & 0.000 \\
\hline Total score of the lexical-semantic subtest & $0.589^{* *}$ & 0.000 & $0.661^{* *}$ & 0.000 \\
\hline
\end{tabular}

Pearson correlation coefficient: $r$ - value shows positive correlation if $>0$ and negative correlation if $<0$ ), p-value is significant at $<0.05$, p-value is highly significant at $<0.01$.

\section{DISCUSSION:}

A crucial and yet complex component of a child's language development is the acquisition of the lexicon (the quantity and the quality of language vocabulary). It is now receiving a growing interest within psycholinguistic research and is becoming a field of study. This is because lexical development interacts with the acquisition processes of the other language domains (form and use) $)^{(11)}$.

Language vocabulary is a useful proxy for general verbal language skills. It is also known as semantic fluency helps in measuring verbal functioning and cognitive flexibility of developing children. Certainly, data from typical development indicates that vocabulary correlates highly with other language abilities and its development is particularly rapid in preschool years ${ }^{(12)}$. Moreover, it is the single best predictor of academic success for children starting school $^{(13)}$.

It is known that the period of word spurt is in the middle of the second year of the child's life. The rate of vocabulary learning continues to be very rapid by the time children reach their third year and a lot of change can occur in few months during this important period of language development. The understanding of the importance of lexical development of preschool children was the motive for this study. Moreover, the lexical semantics of the Arabic-speaking children was not yet comprehensively studied. Thus, this study was done to explore the development of the lexical-semantic among the Egyptian Arabic-speaking children.

This study is the first to study comprehensively the semantic development among Arabic-speaking children. This study focused on assessing the ability of the children to identify and label different noun classes, verbs, and adjectives. These 3 types of lexical semantics are called the lexemes words which represent the early vocabulary heard and learned by children, either at home and/or the nursery environments, starting from their first days of life and among their earlier years. Children use nouns to name the world around them and verbs and adjectives to express their acts and feelings, respectively. Getting knowledge about the development of such semantic nouns helps Phoniatricians and speechlanguage pathologists to determine the deficits and delays among children with communication disorders, particularly delayed language disorders.

This study revealed that children at the age of 2 years started to identify noun and verb classes earlier than adjectives, moreover nouns are richer than verbs. Adjectives started to be acquired at age of 2.6 to 3 years and were mostly identified by the age of 3 to 3.6 years. Two main factors affect the development of the lexical- 
semantic and directed the ability of young children to identify and label the different noun classes. Firstly, young children can understand things based on their perception of the physical world. Entities or things (like tables, chairs, birds, or dogs), in learning nouns, children need only to learn the labels for meanings they already have. They know names for people, food, body parts, clothing, animals, and household items that are involved in their daily routines (14). This could explain the results of this study that revealed children at the age of 2.6 to 3 years can identify most of the lexical noun classes. They could recognize all wild animals, farm animals and birds, insects, vegetables, fruits, clothing items, food, electronic devices, common objects, body parts, colors, and places (receptively).

The second factor that directs the children's lexical semantic development is that younger children start to use their words for a wider range of referents than adults do. This is due to incomplete knowledge of word meaning they have and is defined as the phenomenon of overextension: for example, lemon and orange both were said to be orange. The child does not acquire the complete adult knowledge of a word's meaning all at once. Instead, the child begins to identify the meaning of a word with only one or two of its semantic components or features of meaning then gradually the child adds more and more components until s/he achieves an adult-like knowledge of the word (Semantic feature hypothesis). This explains the incomplete ability of children to identify and/or label nouns under the following lexical noun classes (animals, food, clothing items, means of transportation, furniture, and electronic devices). Little of these lexical noun classes were identified by children of $2-2.6$ years, but they became fully developed as children grow from the age of 3 to 4 years.

For the lexical noun classes (wild animals, farm animals and birds, insects, vegetables, fruits, clothing items, food, electronic devices, common objects, body parts, colors and places) children can identify most of them by the age of 2 years and 6 months to 3 years. On the other hand, Kotby et al. ${ }^{15}$ found that children by the age of 3-4 years know all body parts, clothes, vegetable fruits, furniture, animals, tools, transportation, food utensils, plants, money, and some colors. Kotby et al. ${ }^{15}$ also stated that by the age of 3-4 years children can say some (but not all the whole semantic classes). Most children in the age group from $2 \mathrm{y}$ to 2.5 years old have no clear boundaries between the meaning of vegetables and the meaning of fruits. However, children are more acquainted with fruits than vegetables. Maybe that is because children get in touch with fruits by themselves rather than vegetables which they see more in a chopped and cooked form.

By the age of 2.6 to 3 years, the child can identify all family members, however, the ability to label the kinship of each family member was fully developed by the age of 3.6 to 4 years. Children at the age of 2.6 to 3 years found it difficult to determine the status of a relationship between them and their other siblings. They usually call their brothers/sisters by their real names rather than words that describe their kinship to them (brother/sister). Moreover, children who have no siblings identified brother and sister as boy and girl, respectively.

This study reported that children by the age of 2.6 to 3 years could identify the names of all colors and by the age of 3.6 to 4 years, children could label all the colors. The results of this study were earlier than that by Abo Hassiba et al. ${ }^{\text {(16), }}$ who stated that the child can identify colors at age 3.6 to 3 years and 11 months and expresses the names of colors and shapes at age of 5.6 to 5 years, 11 months. This was unexpected as it is known that colors' names are abstract nouns, and it is easier for young children to identify early 
the concrete nouns (e.g. flower, book) rather than abstract nouns (e.g., shapes, color). However, it was noticed that nowadays parents begin early to learn their children the colors' name to prepare their children for the school interviews. Knowing and labeling colors is one of the skills needed for child acceptance in most national school interviews in Egypt, which starts early by the age of 3.6 and 4 years. Moreover, EAST included the common basic colors (red, blue, yellow, green, white, and black) which are familiar to children, unlike (16) who used difficult colors (such as purple, orange).

The names of the jobs were difficult among preschoolers but as the age increased, most of the children knew names of jobs mainly (doctor, football players, and policeofficer). This is because most children are more acquainted with their pediatricians. Besides, football players and police-officer are the most impressive jobs by Egyptian children, especially male children.

Regards the acquisition of verbs, this study reported children to understand more verbs than they can express them. The results of this study indicating children at the age of 2.6 to 3 years could identify all action verbs. Most primary developed action verbs are those grabbed from the child's daily actions (e.g., eat, drink, comb). This matches with results by ${ }^{(\mathbf{1 4})}$ who reported first verbs include labels for actions that are part of children's routines (e.g., eat, drink, kiss, sing) and verbs with more general meanings that are frequent in children's input (look, go, come, do). Verbs like (read and write) become more evident in group 4 as they learn to write in nurseries, and they start to know what reading and writing are like. by the age of $3 \mathrm{y}$ and 6 months to 4 years, children could label all verbs.

Adjectives start to appear at the age of 2 $\mathrm{y}$ and 6 months to 3 years, by this age the child knows most adjectives receptively (big, dirty, beautiful, cold, clean, ugly, hot). However, they know all adjectives receptively by the age of 3 years to 3 years and 6 months. The ability to label different adjectives and use them (big, small, beautiful, clean, ugly, hot) is more evident by the age of 3 y and 6 months to 4 years. Kotby et al. 15 stated that children understand (big and small at the age of 3-4 years and (tall and short), however, children at this age don't fully understand tall and short and they rather use the easier descriptive words (small and big).

Most children said the opposite of short was "big" rather than "tall". According to Clark's semantic feature hypothesis (18), words expressing more general features are acquired before words expressing specific ones (which occurs in few ones).

\section{Conclusion:}

The obtained results in this research can put the foundation stone on which further research on figuring out the Semantic developmental stages of Egyptian Arabic speaking children could be built. Noun classes and verbs started to be identified by children at the age of 2 years. As the children grow the more nouns and noun classes could be identified and labeled. Adjectives started to be acquired at age of 2.6 to 3 years and were mostly identified by the age of 3 to 3.6 years.

\section{Recommendations:}

Further work needs to be done on Large-scale corpus-based to allow us to shed light on the pattern of preschool lexicalsemantic development among Arabicspeaking children. Early assessment of lexical-semantic abilities helps more in deciding the diagnosis and prognosis of language disorders and drawing the content and design of objective direct intervention language therapy.

\section{REFERENCES:}

1. Lundberg, I. (2002). The child's route into reading and what can go wrong. Dyslexia, 8(1): 1-13. 
2. Lyons, J. (1995). Linguistic Semantics: An Introduction. Cambridge University Press: Cambridge, United Kingdom.

3. Loebner, S. (2013). Understanding Semantics. Arnold Publishers: London, United Kingdom.

4. Cruce, A. (2000). An introduction to Semantics and Pragmatics. Oxford University Press: Oxford, United Kingdom.

5. Odgen, C.K., Richards, I.A. (1923). The meaning of meaning. A study of the influence of language upon thought and the science of symbolism $\left(10^{\text {th }}\right.$ ed.). Routledge and Kegan Paul Ltd: London, United Kingdom.

6. Jackendoff, R. (1983). Semantics and Cognition. Cambridge, Massachusetts: MIT Press.

7. Rambaud, M.G. (2012). Basic Semantics. Universidad Nacional De Educaion a Distancia: Madrid, Spain.

8. Alsayed, F. (2020). The Effects of Semantics in the Language Development of English as a Foreign Language (EFL) Learners. International Journal of Learning and Development, 9, 138. Doi: 10.5296/ ijld.v9i4.15735.

9. Hoff, E., (2008): Lexical Development: Learning Words. In: E. Hoff (Eds.), Language Development $\left(4^{\text {th }}\right.$ ed., pp. 184 219). Michele Sordi, USA.

10. Hanoura, M. A. (2002). Stanford-Binet intelligence test: Arabic version, 5th eds. Anglo Press, Egypt.

11. Salama, H., Alansary, S. (2017). Lexical Growth in Egyptian Arabic Speaking Children: A Corpus-Based Study. The Egyptian Journal of Language Engineering, 4(1), 29-34.

12. Memisevic, H., Biscevic, I., Pasalic, A., Elmer, S. (2017) Developmental trends in semantic fluency in preschoolchildren, Cogent Psychology, 4:1.

13. Eigsti, I.M. (2017). Peabody Picture Vocabulary Test. In: Volkmar F. (eds) Encyclopedia of Autism Spectrum Disorders. Springer, New York, NY. https://doi.org/10.1007/978-1-4614-64358_531-3.

14. Naigles, L. R., Hoff, E. (2006). Verbs at the very beginning: Parallels between comprehension and input. In: K. HirshPasek \& R. M. Golinkoff (Eds.), Action meets word: How children learn verbs (pp. 336-363). New York: Oxford University Press.

15. Kotby, M. N., Khairy, A., Barakah, M., ElRifaie, N., El-Shobary, A. (1995). Language testing in Arabic-speaking children. Proceedings of the XXIII world congress of the international association of Logopedics and Phoniatricians: Cairo, Egypt.

16. Abou Hassiba, A., El Sady, S., Elshobary, A., Gamal Eldin, N., Ibrahiem, A., Oweys, A. (2011). Standardization, Translation, and Modification of the Preschool Language Scale - 4. A Doctoral Dissertation, Faculty of Medicine, Ain Shams University: Cairo, Egypt.

17. Abd El Moneim, D.M., Ghandour, H.H, Elrefaie D.A., Khodeir M.S. (2021). Development and Standardization of an Arabic Semantic Test for Egyptian ArabicSpeaking Children. A Master Dissertation, Faculty of Medicine, Ain Shams University, Cairo, Egypt.

18. Clark, E. V. (1973): whates in a word? On the child"s acquisition of semantics in his first language. In: More, T. (Ed.). Cognitive development and the acquisition of language. New York Academic Press. 


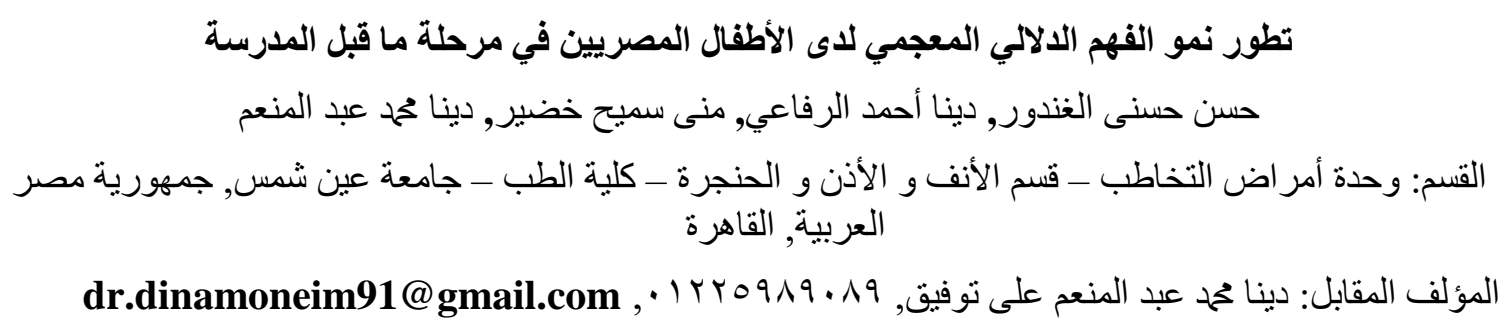

المقدمة: التطوير المعجمي الدلالي لأطفال ما قبل المدرسة له العديد من التطبيقات في تصميم البحث و التقبي التبيم و التدخل

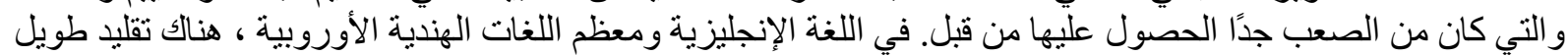

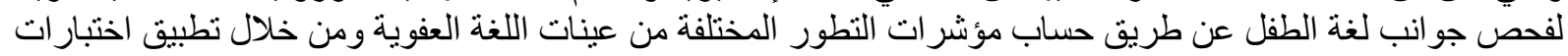

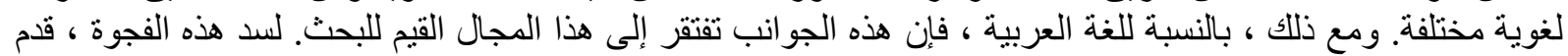

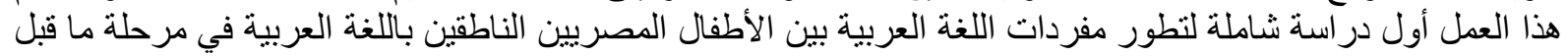
المدرسة.

هدف الدراسة: تقديم لمحة وصفية عن التطور المعجمي الدلالي بين الأطفال المصريين الناطقين بالعربية في مرحلة ما قبل المدرسة.

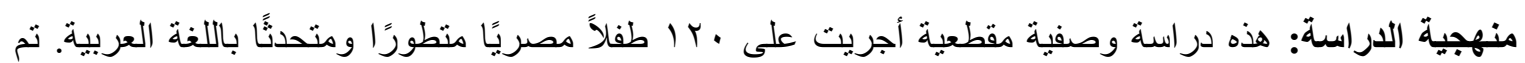

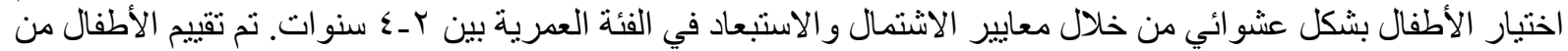

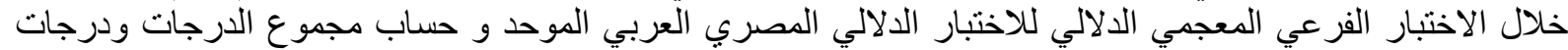

الأطفال في الجو انب الاستقبالية والتعبيرية عن طريق تطبيق جزء الاختبار الفر عي المعجمي الدلالي EAST

$$
\text { ومقارنتها لتحديد تطور المعجم الدلالي بين الفئات العمرية الأربع. }
$$

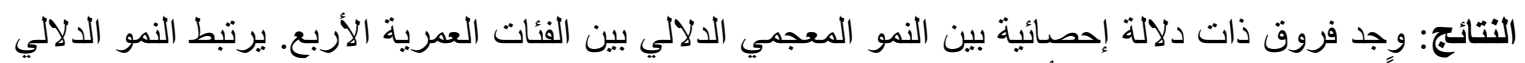
المعجي ارتباطًا إيجابيًا بالعمر الزمني للأطفال المشاركين.

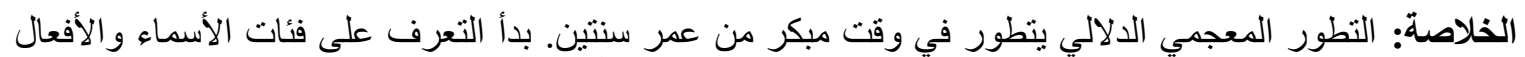

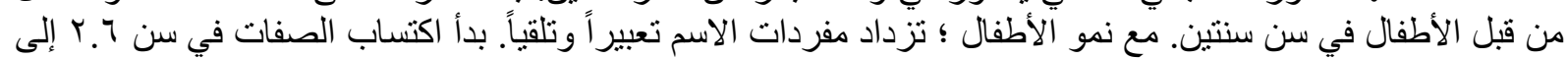

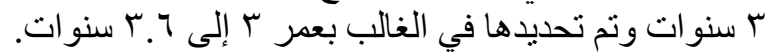

